\title{
Antibiotic Resistance of Enterobacteria present in an Urban Wastewater Treatment Plants: A Public Health Problem
}

\author{
1,2Karina Paredes Páliz, 3Ana María Cunachi, ${ }^{3}$ Lisseth Ortiz Cruz, 1 Fabián Arias
}

${ }^{1}$ Escuela Superior Politécnica de Chimborazo, GIMA (Research Group of Applied Materials), Faculty of Science, Box EC 060155, Riobamba, Ecuador ${ }^{2}$ Universidad de Sevilla, Department of Microbiology and Parasitology, Faculty of Farmacy, Box 41013, Sevilla, Spain.

${ }^{3}$ Escuela Superior Politécnica de Chimborazo, Department of Biological Sciences, Faculty of Natural Resources, Box EC 060155, Riobamba, Ecuador

Correspondence Author: Karina Inés Paredes Páliz, Escuela Superior Politécnica de Chimborazo, Faculty of Science, Box: EC060155, Riobamba, Ecuador. +593 989427444 Riobamba, Ecuador. Panamericana Sur km 1 1/2, Riobamba-Ecuador

Email: kparedes@espoch.edu.ec

Received date: 20 May 2019, Accepted date: 20 July 2019, Online date: 28 July 2019

Copyright: (C) 2019 Karina Paredes Páliz et al., This is an open-access article distributed under the terms of the Creative Commons Attribution License, which permits unrestricted use, distribution, and reproduction in any medium, provided the original author and source are cre dited.

\begin{abstract}
Background: Bacterial resistance to multiple antibiotics is considered one of the most important public health problems in Latin America. In Ecuador, there is a high rate of infectious diseases caused by Enterobacteriaceae which mainly affect the central nervous system, digestive and urinary tract, respiratory system, bloodstream, etc. This type of infections affects children, young people and adults with no effective treatments due to the resistance to even fifth-generation antibiotics. Inadequate procedures for handling and disposal of solid and liquid waste are another cause for the generation of this resistance and its consequences on population health. Urban wastewater treatment plants represent important reservoirs of human and animal commensal bacteria. Objective: The objective of this study was determinate the resistance of Enterobacteria isolated from septic tanks of the Domestic Wastewater Treatment Plant against different commercial antibiotics. Methodology: With $10 \mathrm{~g}$ of residual sludge by the serial dilution method in MacConkey and EMB culture media, isolations of several Enterobacteria were obtained, then, isolates were characterized and subjected to resistance tests using disks of three different antibiotics that are frequently used in infectious treatments caused by Enterobacteria. Results: Sixteen cultures with different morphology were obtained and described as common species genera within the Enterobacteriaceae: Escherichia, Salmonella, Proteus, Klebsiella, Shigella, Enterobacter. Strain 2872 was discarded due to its similar morpho-physiology to 2867 . Thirteen of fifteen strains have tetracycline resistance and only two were inhibited (2873 and 2876); only one of the fifteen were resistant to polymyxin B (2870) and eight were resistant to cefepime. Conclusion: Only polymyxin B could be used for treatment of infections occurred by some of these isolated strains, although its use should be limited due to negative effects related to nephrotoxic and neurotoxic potential.
\end{abstract}

Keywords: Enterobacteriaceae, resistance, antimicrobials, wastewater

\section{INTRODUCTION}

Drug-resistant infections, both in humans and in animals, are increasing worldwide. The main factors that contribute to the emergence and spread of antimicrobial resistance are the excessive and inadequate use of these drugs. In many developing countries, including Ecuador, antibiotics are sold without a prescription, even where laws prohibit this practice. Fake and poorquality antibiotics also contribute to resistance, as does the use of antimicrobials in animal husbandry [1]. Antibiotics are used in excessively and inappropriately. If the antimicrobial resistance spreads without control, many infectious diseases will become intractable again, which will reverse a century of advances in public health [2].

On the other hand, resistance to antibiotics would generate a sharp increase in poverty. Of the 28.3 million people who would fall into extreme poverty by 2050 , in the scenario of high-impact antimicrobial resistance, the clear majority (26.2 million) would live in low-income countries. Currently, the world is well on track, in general terms, to eliminate extreme poverty (calculated based on a threshold of USD 1.90 per day) by 2030 at the latest, given that it is approaching the goal of achieving less of $3 \%$ of people to live in those conditions. That goal could become unattainable due to antibiotic resistance [1]. 
Although bacterial resistance is attributed to purely natural processes due to the ability of bacteria to transfer their genes, it is also true that some inadequate procedures such as incomplete treatment, incorrect doses of antibiotic. Some studies reported that the emergence of resistance to third-generation cephalosporins and carbapenems in Gram-negative isolates might even appear due to the influence of adverse environmental conditions; promote morpho-physiological alterations and expression of genes to guarantee the survival of these microorganisms [3]. The survival of bacteria in other environments depend, however, on many parameters, such as temperature, humidity, $\mathrm{pH}$, soil composition and the presence of the other microorganisms [3].

Frequently, the dispersion of human enteric bacteria occurs through raw sewage are often discharged into low-temperature marine and aquatic environments, raising the question of whether human enteric pathogens (i.e., Salmonella) and indicator organisms (i.e., E. coli) can adapt and persist in these extreme environments. Genomes of these bacteria have more than 1,000 genes, whose functions remain unknown and which could contribute to proliferation in non-host environments, such as soil and water, even in the sludge from the treatment plants, the presence of CFU of Enterobacteria that survive the depurative processes is reported, consequently, they promote the transmission to a new host and the resistance or the prevalence of infectious diseases by resistance [4].

Bacterial resistance to multiple antibiotics is considered one of the most important public health problems in Latin America. In Ecuador, there is a high rate of infectious diseases caused by Enterobacteriaceae at the lower central nervous system and respiratory tract, bloodstream, and digestive and urinary tract, and affects children, youth and adults with no effective treatments due to the resistance even fifth-generation antibiotics, as enterobacteria have an inexhaustible ability to resist antibiotics due to their mutations, acquisition of resistance genes, transposons and integrons, affecting the health of population [5,6]. Since the appearance of the first antibiotics in the 20th century, bacterial resistance to these drugs has been a controversial subject that until today has not been fully elucidated, by the resistance as a natural expression of evolution and its bacterial genetics [7]. Antibiotics considered first-generation, and the current denominated ones of fourth, usually are not completely efficient when dealing with certain infectious processes caused by enterobacteria capable of resisting multiple drugs, due to the indiscriminate use of these, not only in developing countries, where antibiotics are available without a prescription, but also in first world countries, where their supply is carried out under stricter controls [8].

In this context, the presence of the genera Escherichia, Klebsiella, Enterobacter, Serratia and Citrobacter (collectively called the coliform bacilli) and Proteus, include overt and opportunistic pathogens responsible for a wide range of infections. Many species are members for the normal intestinal flora, but $E$. coli is very frequently isolated from other organisms and different environments [9].

Throughout history, there has been a significant increase in bacterial resistance to antimicrobials, an effect that has generated great concern as the main obstacle in the treatment and containment of infectious etiologies. Being also of interest for the development of new therapeutic strategies [10].

Urban wastewater treatment plants (UWTPs) are among the main sources of antibiotics' release into various compartments of the environment worldwide. The treatment of this UWTPs is fundamental to ensuring the public health and environmental protection [11].

Bacterial dissemination by any means is undoubtedly the main reason for the generation of resistance, even though several procedures are performed without the respective control and the manipulation is carried out without the minimum required considerations, as with biosolids from domestic wastewater treatment plants, which are deposited in sanitary landfills and/or controlled landfills, can infiltrate and reach groundwater or to be transported by wind and water erosion and consequently disseminate the microbial load present in this material [11]. For all the above, the main objective of this study was to determine the population of Enterobacteria present in a biosolid from the septic tanks of the Domestic Wastewater Treatment Plant "El Peral" in Ambato city, Tungurahua. Ecuador.

\section{MATERIALS AND METHODS}

\section{Study area and Sampling collection.}

The study was carried out at Ambato city, Tungurahua. Ecuador, in the Domestic Wastewater Treatment Plant "El Peral" (17M 9863047.72S 763693.43 E). Fig.1. Sludge samples were randomly collected at four specific points to obtain a composite sample; this procedure was performed once a week for 17 weeks.

The composite sample $(2 \mathrm{Kg})$ was placed in a ziploc sheath, stored and transported at $4{ }^{\circ} \mathrm{C}$ to the Laboratory of Biological Sciences (ESPOCH) for analysis. 
Fig. 1: Domestic wastewater treatment plant. "El Peral".

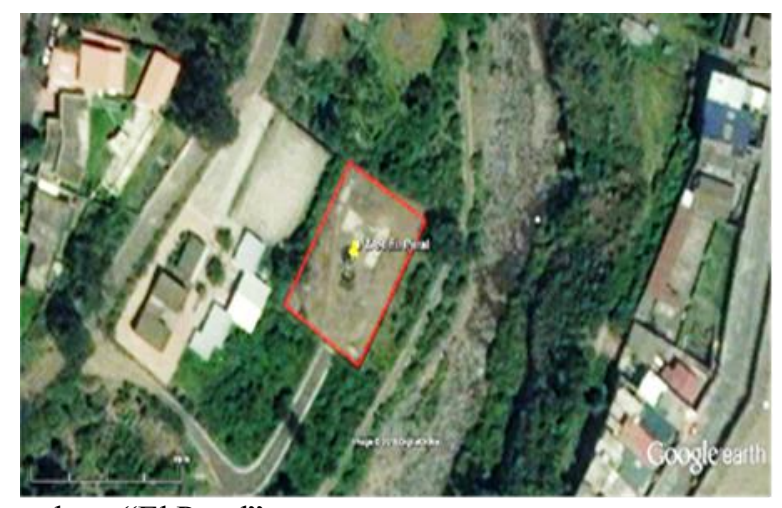

\section{Physicochemical analysis.}

Physicochemical analysis was performed in the soil laboratory (ESPOCH), from $1 \mathrm{~kg}$ of composite sample, $\mathrm{pH}$, organic matter, electrical conductivity, moisture, nitrogen, phosphorus, potassium, calcium and carbon/nitrogen ratio were determined using standardized methods, APHA for $\mathrm{pH}$, electrical conductivity, moisture and OLSEN method for the other parameters considered.

\section{Microbiological analysis.}

In the microbiological analysis, $1 \mathrm{~kg}$ of composite samples, was homogenized and using the method of serial dilution, $50 \mu 1$ of dilutions $10^{-1}$ to $10^{-6}$ were inoculated in Eosin Methylene Blue Agar medium (EMBA) and MacConkey Agar, then the petri dishes were incubated during $72 \mathrm{~h}$ at $37^{\circ} \mathrm{C}$; at which time the $\mathrm{CFU}$ of enterobacteria present in the sample was determined.

\section{Morphological and physiological characterization.}

For the description of the morphology of the bacterial colonies, pure cultures were obtained in the EMBA and MacConkey agar, and the description was made based on the specific characteristics established for each of the genera of enterobacteria in these selective culture media [12].

\section{Bacterial resistance test.}

Disc Diffusion Method for Antimicrobial Susceptibility Testing was used for bacterial resistance test. One dilution 1:100 was prepared from each strain and adjusted to that of a $0.5 \mathrm{McFarland}$ standard in distilled water. After, these suspensions were used to inoculate the petri dishes by dipping a sterile cotton-wool swab into the suspension and remove the excess liquid by turning the swab against the side of the container. Spread the inoculum evenly over the entire surface of the plate by swabbing in three directions. Allow the plate to dry before applying discs [13].

Whatman paper discs of $6 \mathrm{~mm} \varnothing$ were submerged in tetracycline $(1 \mathrm{mg} / \mathrm{ml})$, polymyxin $\mathrm{B}(1 \mathrm{mg} / \mathrm{ml})$ and cefepime $\left(1 \times 10^{3}\right.$ $\mathrm{mg} / \mathrm{ml}$ ) and stored to at $<8^{\circ} \mathrm{C}$, for one hour and then the discs were firmly and evenly applied to the dry surface of inoculated Petri dishes.

Fifteen minutes after placing the discs proceeded to the incubation at $37^{\circ} \mathrm{C}$ for $48 \mathrm{~h}$, completed incubation, the measurement of the diameters of inhibition zones ( $\mathrm{mm}$ ) and the interpretation of the susceptibility [13 y 14].

\section{RESULTS AND DISCUSSION}

\section{Physicochemical analyses.}

Results obtained in the physicochemical analyses show that the sludge has a pH varying from 5.05 to 6.92 ; humidity is often above $61 \%$; and the contents of N, P, K and Ca do not exceed 5\%; also, the carbon/nitrogen ratio is very low (Table 1).

Acid to neutral range in $\mathrm{pH}$ is considered adequate for the growth of microorganism including coliforms, whose optimum $\mathrm{pH}$ goes from 7.0 to 7.5. Nevertheless, these adapt and grow until a minimum pH of 4 and a maximum of 8.5 [15]. The percentage of moisture recorded in these sludges, considered high, directly affects the mobility of both the biological load and chemical elements presents [16]. Although intermediate humidities (40-60\%) are lethal for some bacteria, on the contrary, high or low humidities favor several processes including the biological ones [17] as evidenced in this research with the abundant growth of Enterobacteria. Not even the low amount of N, P, K and $\mathrm{Ca}$ as well as the $\mathrm{C} / \mathrm{N}$ ratio that evidences the low availability of nutrients that may favourable for the activity of certain groups of microorganisms but detrimental to others, however, they growth of Enterobacteria has not been affected under the physicochemical conditions described for these sludge to be an atypical environment, these results are in agreement with [2], which claim that these microorganisms have induced survival complexes under adverse conditions. Another of the options is that the Enterobacteria throughout their evolution can develop biphasic lifestyles, consisting of host-independent and host-associated phases, thus surviving in open environments [18]. Even if there were no optimal or favorable conditions, especially the bacteria develop the ability to adapt and colonize new niches, particularly, bacteria develop capacities to survive, consequently, resistance is generated that is sometimes attributed to the insertion of mobile genetic fragments which can even be widely distributed in other domains of life [19]. 
Table 1: Values of some physical-chemical parameters of the sludge from the domestic wastewater treatment plant "El Peral".

\begin{tabular}{|c|c|c|c|c|c|c|c|c|c|}
\hline Sample & $\mathrm{pH}$ & \% OM & $\mathrm{mS}$ EC & \% Humidity & \% N & \% P & \% K & \% C & $\mathrm{C}: \mathrm{N}$ \\
\hline 1 & 6.92 & 3.7 & 3.27 & 51.99 & 1.0 & 0.54 & 0.07 & 0.9 & $2: 1$ \\
\hline 2 & 5.05 & 3.5 & 3.20 & 52.85 & 0.43 & 2.2 & 0.21 & 0.9 & 1.3 \\
\hline 3 & 6.10 & 4.2 & 3.38 & 56.89 & 0.54 & 2.7 & 0.26 & 1.7 & 1.8 \\
\hline 4 & 5.56 & 6.1 & 3.40 & 57.44 & 0.61 & 3.0 & 0.41 & 2.0 & 1.6 \\
\hline 5 & 6.58 & 7.6 & 3.46 & 59.77 & 0.63 & 3.9 & 0.44 & 2.3 & 2.0 \\
\hline 6 & 5.05 & 3.5 & 3.20 & 52.85 & 0.43 & 2.2 & 0.21 & 0.9 & 1.3 \\
\hline 7 & 6.10 & 4.2 & 3.38 & 56.89 & 0.54 & 2.7 & 0.26 & 1.7 & 1.8 \\
\hline 8 & 5.56 & 6.1 & 3.40 & 57.44 & 0.61 & 3.0 & 0.41 & 2.0 & 1.6 \\
\hline 9 & 6.58 & 7.6 & 3.46 & 59.77 & 0.63 & 3.9 & 0.44 & 2.3 & 2.0 \\
\hline 10 & 6.10 & 3.4 & 3.30 & 53.10 & 0.36 & 2.0 & 0.12 & 0.8 & 1.3 \\
\hline 11 & 6.92 & 4.0 & 3.41 & 58.02 & 0.31 & 2.0 & 0.19 & 1.0 & 1.4 \\
\hline 12 & 6.76 & 5.8 & 3.43 & 59.89 & 0.37 & 2.7 & 0.33 & 1.2 & 1.7 \\
\hline 13 & 6.75 & 7.4 & 3.50 & 61.29 & 0.39 & 3.0 & 0.38 & 1.9 & 1.9 \\
\hline 14 & 6.10 & 3.4 & 3.30 & 53.10 & 0.36 & 2.0 & 0.12 & 0.8 & 1.3 \\
\hline 15 & 6.92 & 4.0 & 3.41 & 58.02 & 0.31 & 2.0 & 0.19 & 1.0 & 1.4 \\
\hline 16 & 6.76 & 5.8 & 3.43 & 59.89 & 0.37 & 2.7 & 0.33 & 1.2 & 1.7 \\
\hline 17 & 6.75 & 7.4 & 3.5 & 61.29 & 0.39 & 3.0 & 0.38 & 1.9 & 1.9 \\
\hline
\end{tabular}

All the samples had a $\mathrm{pH}$ range around de acid, and tending to neutral, although [20 y 21] reported the growth of Enterobacteria from environmental samples, at an average $\mathrm{pH}$ value of 8.4. Likewise, the content of organic matter and macro elements such as nitrogen are related since about $10 \%$ is in the form of ammonium nitrogen and the rest is linked to the organic fraction for mineralization processes, as mentioned [22].

\section{Microbiological analysis.}

All the sludge samples presented a growth of colonies of Enterobacteria in the two-culture media used, the most abundant morphologies in both EMB agar and MacConkey agar were those described for the genera Proteus, Enterobacter, Klebsiella and Escherichia and in a smaller amount the growth of Salmonella and Shigella colonies Fig. 2.

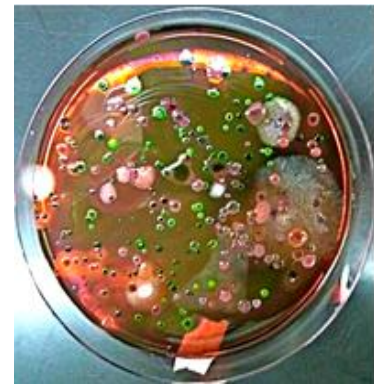

(a)

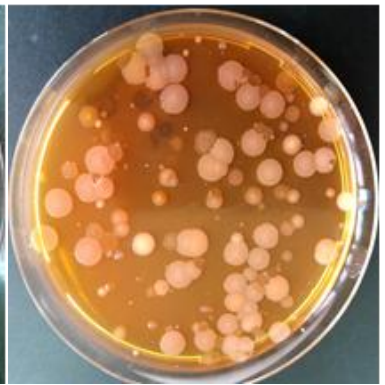

(b)

Fig. 2: Colonies of enterobacteria. a) EMB agar. b) MacConkey agar.

The genera Proteus and Escherichia were the most abundant genotypes in the 17 analyzed samples, the genus Enterobacter/Klebsiella, Salmonella/Shigella growth was smaller, but the trend was similar in the two-culture media (Table 2).

Table 2: Colony Forming Units (CFU)/g of Enterobacteria from sludge in EMB agar and MacConkey agar, quantified at $72 \mathrm{~h}$ incubation.

\begin{tabular}{|c|c|c|c|c|c|c|c|c|}
\hline Sample & \multicolumn{2}{|c|}{ Proteus } & \multicolumn{2}{c|}{ Enterobacter/Klebsiella } & \multicolumn{2}{c|}{ Escherichia coli } & \multicolumn{2}{c|}{ Salmonella/Shigella } \\
\hline & $\mathbf{1}$ & $\mathbf{2}$ & $\mathbf{1}$ & $\mathbf{2}$ & $\mathbf{1}$ & $\mathbf{2}$ & $\mathbf{1}$ & $\mathbf{2}$ \\
\hline 1 & $8.6 \times 10^{6}$ & $7.3 \times 10^{6}$ & $4.3 \times 10^{6}$ & $3.8 \times 10^{6}$ & $3.5 \times 10^{6}$ & $3.5 \times 10^{6}$ & $1.5 \times 10^{6}$ & $1.5 \times 10^{6}$ \\
\hline 2 & $6.5 \times 10^{6}$ & $7.3 \times 10^{6}$ & - & - & $2.5 \times 10^{6}$ & $2.1 \times 10^{6}$ & - & - \\
\hline 3 & $4.8 \times 10^{6}$ & $5.3 \times 10^{6}$ & - & - & $4.0 \times 10^{6}$ & $4.7 \times 10^{6}$ & - & - \\
\hline 4 & $5.0 \times 10^{6}$ & $5.5 \times 10^{6}$ & - & - & $3.5 \times 10^{6}$ & $4.1 \times 10^{6}$ & - & - \\
\hline 5 & $2.5 \times 10^{7}$ & $2.1 \times 10^{7}$ & - & - & $8.0 \times 10^{6}$ & $8.3 \times 10^{6}$ & $4.1 \times 10^{6}$ & $4.6 \times 10^{6}$ \\
\hline 6 & - & - & - & - & $6.0 \times 10^{6}$ & $5.5 \times 10^{6}$ & - & - \\
\hline 7 & $2.5 \times 10^{5}$ & $2.0 \times 10^{5}$ & - & - & $5.3 \times 10^{5}$ & $6.0 \times 10^{5}$ & - & - \\
\hline 8 & $1.5 \times 10^{6}$ & $1.9 \times 10^{6}$ & - & - & $3.5 \times 10^{6}$ & $3.0 \times 10^{6}$ & - & - \\
\hline 9 & $2.0 \times 10^{7}$ & $2.4 \times 10^{7}$ & - & - & $8.0 \times 10^{6}$ & $7.4 \times 10^{6}$ & $4.0 \times 10^{6}$ & $4.3 \times 10^{6}$ \\
\hline 10 & $1.0 \times 10^{3}$ & $1.6 \times 10^{3}$ & - & - & $5.2 \times 10^{6}$ & $5.9 \times 10^{6}$ & $1.1 \times 10^{3}$ & $1.0 \times 10^{3}$ \\
\hline
\end{tabular}




\begin{tabular}{|c|c|c|c|c|c|c|c|c|}
\hline 11 & $1.8 \times 10^{3}$ & $1.3 \times 10^{3}$ & - & - & $3.2 \times 10^{4}$ & $2.9 \times 10^{4}$ & $1.1 \times 10^{2}$ & $1.0 \times 10^{2}$ \\
\hline 12 & $2.4 \times 10^{3}$ & $2.8 \times 10^{3}$ & - & - & $2.5 \times 10^{5}$ & $2.8 \times 10^{5}$ & $1.0 \times 10^{2}$ & - \\
\hline 13 & $3.1 \times 10^{3}$ & $2.7 \times 10^{3}$ & - & - & $1.5 \times 10^{3}$ & $1.1 \times 10^{5}$ & $1.0 \times 10^{2}$ & $1.1 \times 10^{2}$ \\
\hline 14 & - & - & $>300$ & $>300$ & - & - & - & - \\
\hline 15 & - & - & $>300$ & $>300$ & - & - & - & - \\
\hline 16 & - & - & $>300$ & $>300$ & - & - & - & - \\
\hline 17 & - & - & $>300$ & $>300$ & - & - & - & - \\
\hline
\end{tabular}

1: EMB agar- (absence of colonies)

2: MacConkey agar

In this case, E. coli is the most abundant bacterium with a growth average of $7.7 \times 10^{6} \mathrm{CFU} / \mathrm{g}$. Studies carry out by [23], in which analyzes the quantity of Enterobacteria present in waste water treatment plants of milk industry, show that the most abundant bacterium is also E. coli, with an average of $2.6 \times 10^{7} \mathrm{CFU} / \mathrm{g}$. These results indicate that the residuality of Enterobacteria is high, regardless of the type of industry, which generates a concern due to inadequate process in waste treatments and the resistance they generate against the antibiotics whit which infectious diseases are treated.

Data reported by $[24,25]$ shows diversity and mentions the predominant microbial consortium in sludge from treatment plants, describing the presence of the phylum Proteobacteria, Gammaproteobacteria class. In the same way, studies made by [26, $27,28]$ affirms the presence of gram-negative including Enterobacteria from clinical and animal origin and who can play a role in the electrochemical reduction of oxygen and in extracellular iron reduction but that also present mechanisms of resistance even against third-generation cephalosporins.

\section{Morphological and physiological characterization.}

EMB agar is one of the culture media considered to be selective for the isolation of Gram-negative bacteria. EMB contains methylene blue and eosin, which inhibit gram-positive bacteria. These dyes also act as differential indicators in response to the fermentation of lactose or sucrose by microorganisms. Coliforms produce bluish-black colonies, while Salmonella and Shigella colonies are colorless or transparent amber. Escherichia coli colonies may exhibit a characteristic metallic green luster due to rapid fermentation of lactose [12].

MacConkey agar is other standard media used for the isolation of Gram-negative bacteria from clinical specimens and various non-clinical materials, on this medium, all organisms of the family Enterobacteriaceae will grow [29 y 30$]$.

Typical colonial morphology of E. coli is pink to rose-red colonies; Enterobacter/Klebsiella are colonies pink but mucoid, Salmonella/Shigella are colorless colonies sometimes are orange to amber and Proteus is colorless colonies [11 y 12]. Sixteen cultures with different morphology were obtained, Gram staining was performed for the description of microscopic morphology, and all were Gram-negative bacilli, later these were codified and stored for later studies Fig. 3.

Strains coded from 2867 to 2882 were used for the antibiosis test against three different antibiotics except for the strain 2872 which was discarded from the study because it presents morpho-physiology like that of strain 2867.
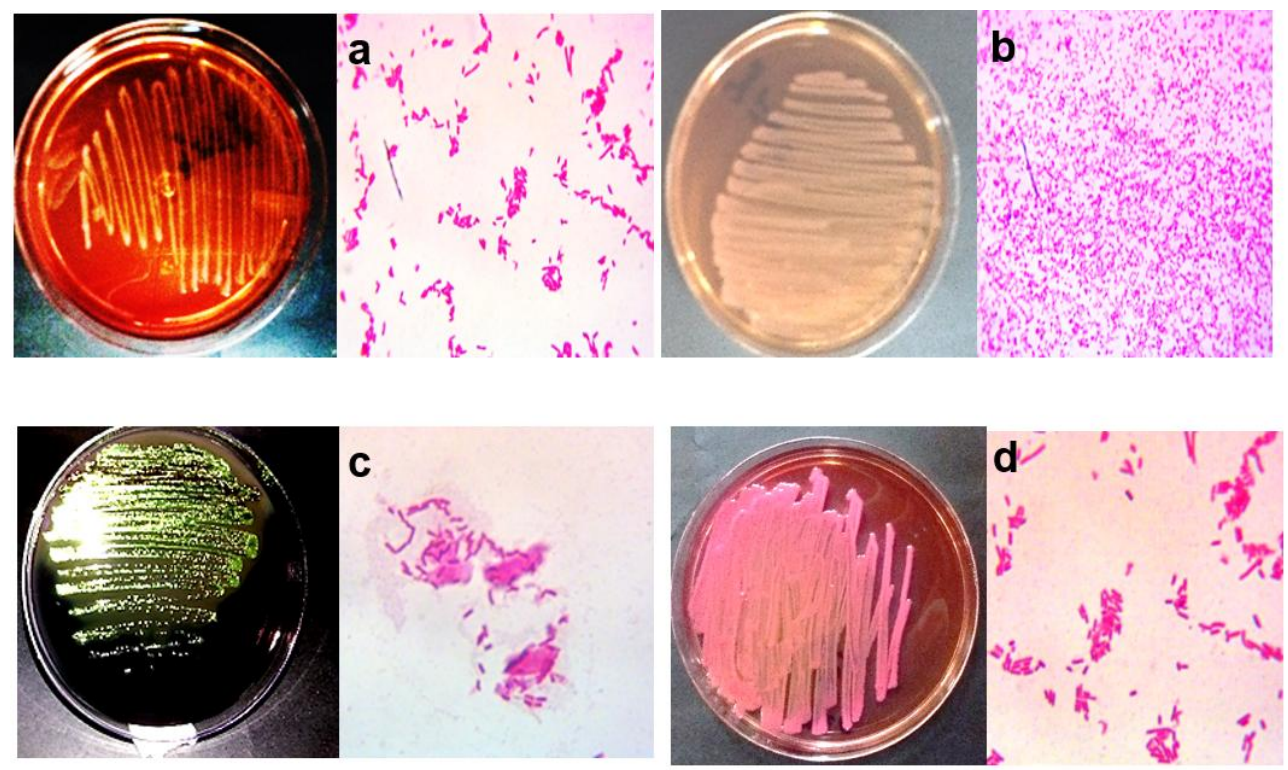

Fig. 3: Gram stain of enterobacteria. a) Klebsiella G- (EMB); b) Salmonella G- (MacConckey); c) Escherichia coli G- (EMBA); Enterobacter G- (MacConkey).

Tetracycline (first generation antibiotic), Polymyxin B (Lipopeptides) and Cefepime (Cefalosporina, fourth-generation), were used at high concentrations to check the sensitivity or resistance of strains of Enterobacteria isolated from sludge by measuring the inhibition halo in colony growth Fig. 4. 


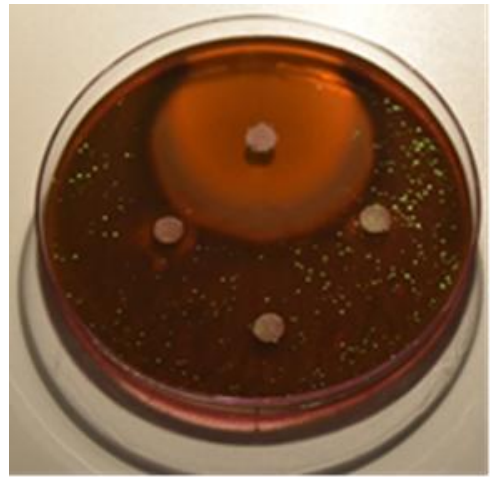

(a)

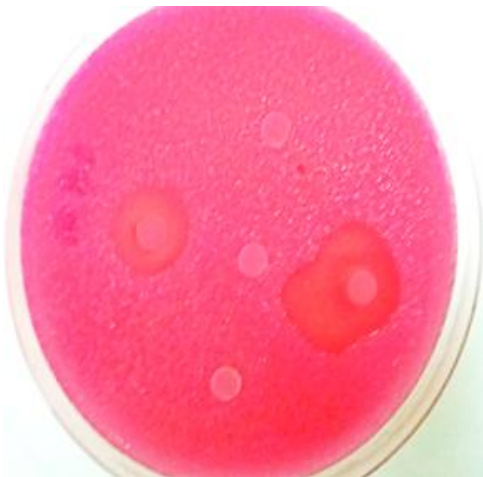

(b)

Fig. 4: Antibiogram of strain 2882 Escherichia coli. a) EMB: Cefepime (25 mm), Polymyxin B (7 mm), Tetracycline (0 mm) and Control (0 mm). b) MacConkey: Cefepime (15 mm), Polymyxin B $(11 \mathrm{~mm})$, Tetracycline $(0 \mathrm{~mm})$, and Control (0 mm).

Thirteen of fifteen strains showed tetracycline resistance and only two were inhibited (2873 and 2876), only one of the fifteen were resistant to polymyxin B (2870) y fourteen were inhibited, eight were resistant to cefepime and seven were inhibited (Table 3).

Most strains (13) were resistant to tetracycline and eight to cefepime, while polymyxin B if it inhibited the growth of 14 strains and only one was resistant. These results show that if an infection occurred because of these strains, only polymyxin B could be used for treatment. However, their use is limited by side effects related to its nephrotoxic and neurotoxic potential.

Tetracycline could not be used to treat infection due to any of the 13 resistant strains, suggesting that one of the mechanisms of resistance developed by these strains in the increased efflux of antibiotics. In this mechanism the membrane expels from the bacterial cell the antibiotic that could have entered, avoiding that it reaches its site of action, is a very common mechanism and can occur both al the chromosomal and plasmid level [31]. Many genes are associated with mobile plasmids, transposons, and conjugative transposons, some of which affect the coding of some protein that protects the bacterial ribosome, or inactivate enzymes, can even use some other mechanism not yet described [32]. Since tetracyclines, such as tetracycline, chlortetracycline, doxycycline, or minocycline act upon the conserved sequences of the $16 \mathrm{~S}$ rRNA of the $30 \mathrm{~S}$ ribosomal subunit to prevent binding of t-RNA to the A specific site [33].

On the other hand, Cefepime is an antibiotic of more rapid penetration, more resistant to inactivation and can choose as targets to multiple proteins of union considered essential [34]; and showed efficacy against 7 strains of Enterobacteria obtained, however, resistance to this broad-spectrum antibiotic was also recorded in 8 strains which suggests that any of the three mechanisms of resistance, inactivation, efflux and site-specific alterations of action could be present, even the expression or repression of genes essential for the production of $\beta$-Lactamase could influence reducing or canceling the effectiveness of this cephalosporin $[35,36]$. However, at least the seven isolates obtained in this work could be controlled with the use of this antibiotic and improve its effectiveness by combining cefepime and zidebatam to achieve better results as reported in the study conducted by [37].

Table 3. Enterobacteriaceae is resistant to Tetracycline, Polymyxin B and Cefepime. Inhibition zone in $\mathrm{mm}$.

\begin{tabular}{|l|c|c|c|c|c|c|c|}
\hline Code & Tetracycline & Polymyxin B & Cefepime & Code & Tetracycline & Polymyxin B & Cefepime \\
\hline 2867 & $\checkmark$ & ++ & $\checkmark$ & 2876 & + & ++ & ++ \\
\hline 2868 & $\checkmark$ & ++ & $\checkmark$ & 2877 & $\checkmark$ & + & ++ \\
\hline 2869 & $\checkmark$ & +++ & $\checkmark$ & 2878 & $\checkmark$ & ++ & + \\
\hline 2870 & $\checkmark$ & $\checkmark$ & $\checkmark$ & 2879 & $\checkmark$ & + & + \\
\hline 2871 & $\checkmark$ & ++ & $\checkmark$ & 2880 & $\checkmark$ & ++ & + \\
\hline 2873 & ++ & ++ & $\checkmark$ & 2881 & $\checkmark$ & + & ++ \\
\hline 2874 & $\checkmark$ & ++ & $\checkmark$ & 2882 & $\checkmark$ & + & ++ \\
\hline 2875 & $\checkmark$ & ++ & $\checkmark$ & & & & \\
\hline
\end{tabular}

$\checkmark$ Resistance Inhibition range

$+1-5 \mathrm{~mm}$

$++6-10 \mathrm{~mm}$

$+++>10 \mathrm{~mm}$

Just one strain (2870) showed resistance to the three antibiotics used in this study, particularly, the resistance to polymyxin can be attributed to modifications of the outer membrane lipopolysaccharide of bacteria as described [38] but it has also been described chromosomal and plasmid-mediated resistance as they describe [39] while fourteen strains were susceptible to this antibiotic. On the other hand, resistance to tetracycline can attributed to the acquisition of new genes, which code for energydependent efflux of tetracycline, or for a protein, that protects bacterial ribosomes as reported [40]. 


\section{CONCLUSION}

According to our results, the presence, ability to survive and resistance to antibiotics shown by several strains of Enterobacteria, isolated from the samples of the sludge object of our study, we can conclude that the risks for public health are still present due to the poor management of urban wastewater treatment plants, which have been subjected to several processes such as the elimination of physical, chemical and biological contaminants. The microbial load present and reported in this study shows the deficiencies in certain procedures that are not completely optimal and directly affect the quality of the health of a population, considering that water and sanitation are the main engines of good public health. However, this being the first report of Enterobacteriaceae in sludge samples from the domestic wastewater treatment plant "El Peral", further studies are necessary to isolate, identify and establish the role of this bacterial group in the microbiota of the sludge as well as their real impact on other ecosystems and the population of the sector.

\section{ACKNOWLEDGEMENT}

This study was accomplished in the Biological Sciences Laboratory at the Escuela Superior Politécnica de Chimborazo (ESPOCH), Riobamba. Ecuador.

\section{CONFLICT OF INTEREST}

Authors declare no conflict of interest

\section{REFERENCES}

1. Sakeena, M. H. F., A. A. Bennett and A. J. McLachlan, 2018. Non-prescription sales of antimicrobial agents at community pharmacies in developing countries: a systematic review. International Journal of Antimicrobial Agents.

2. Ventola, C. L., 2015. The antibiotic resistance crisis: part1: causes and threats. Pharmacy and therapeutics, 40(4):277.

3. Vikesland, P., E. Garner, S. Gupta, S. Kang, A. Maile-Moskowitz, and N. Zhu, 2019. Differential Drivers of Antimicrobial Resistance across the World. Accounts of Chemical Research.

4. Hassard, F., A. Andrews, D. L. Jones, L. Parsons, V. Jones, B.A. Cox and S. K. Malham, 2017. Physicochemical factors influence the abundance and culturability of human enteric pathogens and fecal indicator organisms in estuarine water and sediment. Frontiers in microbiology, 8.1996.

5. Rocha, C., N. D. Reynolds and M. P. Simons, 2015. Resistencia emergente a los antibióticos: una amenaza global y un problema crítico en el cuidado de la salud. Revista Peruana de Medicina Experimental y Salud Pública, 32:139-145.

6. López-Velandia, D. P., M. I. Torres-Caycedo and C. F. Prada-Quiroga, 2016. Genes de resistencia en bacilos Gram negativos: Impacto en la salud pública en Colombia. Universidad y Salud, 18(1),190-202.

7. Klein, E. Y., T. P. Van Boeckel, E. M. Martinez, S. Pant, S. Gandra, S. A. Levin and R. Laxminarayan, 2018. Global increase and geographic convergence in antibiotic consumption between 2000 and 2015. Proceedings of the National Academy of Sciences, 115(15): E3463-E3470.

8. Landecker, H., 2016. Antibiotic resistance and the biology of history. Body and Society, 22(4):19-52.

9. Kim, S., A. Covington and E. G. Pamer, 2017. The intestinal microbiota: antibiotics, colonization resistance, and enteric pathogens. Immunological Reviews, 279(1):90-105.

10. Torres-Caycedo, M. I., L. T. Castro-Gutiérrez, C. F. Prada-Quiroga and D. P. López-Velandia, 2018. Antibiotic Resistance: Origins, evolution and healthcare-associated infections. Revista Científica Salud Uninorte, 34(2): 494-505.

11. Manaia, C. M., J. Rocha, N. Scaccia, R. Marano, E. Radu, F. Biancullo and I. Kampouris, 2018. Antibiotic resistance in wastewater treatment plants: tackling the black box. Environment International, 115:312-324.

12. Dortet, L., L. Bréchard, L. Poirel and P. Nordmann, 2014. Impact of the isolation medium for detection of carbapenemaseproducing Enterobacteriaceae using an update version of the Carba NP test. Journal of Medical Microbiology, 63:772-776.

13. Wotton, M., 2013. Methods for Antimicrobial Susceptibility Testing. British Society for Antimicrobial Chemotherapy, 13, 187.

14. Hombach, M., P. Courvalin and E. C. Böttger, 2014. Validation of antibiotic susceptibility testing guidelines in a routine clinical microbiology laboratory exemplifies general key challenges in setting clinical breakpoints. Antimicrobial Agents and Chemotherapy, 58(7): 3921-3926.

15. Galvis Toro, J., X. Rivera Guerrero, 2013. Caracterización físicoquímica y microbiológica de los lodos presentes en la planta de tratamiento de aguas residuales industriales (PTARI) de la empresa jugos Hit de la ciudad de Pereira (Doctoral dissertation, Pereira: Universidad Tecnológica de Pereira).

16. Kalinichenko, K., G. Nikovskaya and Z. Ulberg, 2016. Actual ecologically friendly solving of problem of municipal sludge. In Litteris et Artibus. Lviv Polytechnic Publishing House.

17. Simantiraki, F., C. G. Kollias, D. Maratos, J. Hahladakis and E. Gidarakos, 2013. Qualitative determination and application of sewage sludge and municipal solid waste compost for BTEX removal from groundwater. Journal of Environmental Chemical Engineering, 1(1-2):9-17. 
18. Van Elsas, J. D., A. V. Semenov, J. T. Trevors, 2011. Survival of Escherichia coli in the environment: fundamental and public health aspects. The ISME Journal, 5(2):173-183.

19. Vandecraen, J., M. Chandler, A. Aertsen and R. Van Houdt, 2017. The impact of insertion sequences on bacterial genome plasticity and adaptability. Critical Reviews in Microbiology, 43(6): 709-730.

20. Lourenço, H. G. G. S., C. K. Takahashi, T. F. Lopes and C. A. D. M, Lopes, 2007. Environmental parameters and antimicronial susceptibility of Enterobacteriaceae isolated from estuarine waters of São Vicente, São Paulo State, Brazil. Journal of Venomous Animals and Toxins including Tropical Diseases, 13(2), 472-478.

21. Chen, Y., S. Lan, L. Wang, S. Dong, H. Zhou, Z. Tan and X. Li, 2017. A review: driving factors and regulation strategies of microbial community structure and dynamics in wastewater treatment systems. Chemosphere, 174, 173-182.

22. Kirchmann, H., G. Börjesson, T. Kätterer and Y. Cohen, 2017. From agricultural use of sewage sludge to nutrient extraction: A soil science outlook. Ambio, 46(2), 143-154.

23. Murcia, J. J., M. Hernández-Laverde, H. Rojas, E. Muñoz, J. A. Navío and M. C. Hidalgo, 2018. Study of the effectiveness of the flocculation-photocatalysis in the treatment of wastewater coming from dairy industries. Journal of Photochemistry and Photobiology A: Chemistry, 358, 256-264.

24. Cydzik-Kwiatkowska, A., and M. Zielińska, 2016. Bacterial communities in full-scale wastewater treatment systems. World Journal of Microbiology and Biotechnology, 32(4), 66.

25. He, Q., J. Zhou, H. Wang, J. Zhang and L. Wei, 2016. Microbial population dynamics during sludge granulation in an A/O/A sequencing batch reactor. Bioresource Technology, 214, 1-8.

26. Chen, Y., S. Lan, L. Wang, S. Dong, H. Zhou, Z. Tan and X. Li, 2017. A review: driving factors and regulation strategies of microbial community structure and dynamics in wastewater treatment systems. Chemosphere, 174, 173-182.

27. Park, Y., H. Cho, J. Yu, B. Min, H. S. Kim, B. G. Kim and T. Lee, 2017. Response of microbial community structure to preacclimation strategies in microbial fuel cells for domestic wastewater treatment. Bioresource Technology, 233, 176-183.

28. Caltagirone, M., E. Nucleo, M. Spalla, F. Zara, F. Novazzi, V. M. Marchetti and G. Pilla, 2017. Occurrence of extended spectrum $\beta$-lactamases, KPC-Type, and MCR-1.2-producing enterobacteriaceae from wells, river water, and wastewater treatment plants in Oltrepò Pavese area, Northern Italy. Frontiers in Microbiology, 8, 2232.

29. Murray, P.R., E.J. Baron, J.H. Jorgesen, M.A. Pfaller and R.H. Yolken, 2003. Manual of Clinical Microbiology, 8th ed., vol. 1, pp. $654-671$.

30. Chika, E., I. Ifeanyichukwu, D. Carissa, A. Thomas, O. Okoro, E. Joshua and E. Charles, 2016. Occurrence of Metallo-BetaLactamase-Producing Enterobacteriaceae from a Local Poultry Farm in Abakaliki, Nigeria. International Journal of Applied Pharmaceutical Sciences and Research, 1(2), 70-75.

31. Li, X. Z., P. Plésiat and H. Nikaido, 2015. The challenge of efflux-mediated antibiotic resistance in Gram-negative bacteria. Clinical Microbiology Reviews, 28(2), 337-418.

32. Roberts, M. C., and S. Schwarz, 2017. Tetracycline and chloramphenicol resistance mechanisms. In Antimicrobial drug resistance Springer, Cham, pp, 231-243.

33. Kapoor, G., S. Saigal and A. Elongavan, 2017. Action and resistance mechanisms of antibiotics: A guide for clinicians. Journal of Anaesthesiology, Clinical Pharmacology, 33(3), 300.

34. Liu, L., J. Yu, M. Tang and J. Liu, 2018. Mechanisms of Resistance in Clinical Isolates of Enterobacter cloacae that Are Less Susceptible to Cefepime than to Ceftazidime. Annual Clinical Laboratory Science, 48(3),355-362.

35. Dobias, J., V. Dénervaud-Tendon, L. Poirel and P. Nordmann, 2017. Activity of the novel siderophore cephalosporin cefiderocol against multidrug-resistant Gram-negative pathogens. European Journal of Clinical Microbiology and Infectious Diseases, 36(12), 2319-2327.

36. Woodworth, K. R., M. S. Walters, L. M. Weiner, J. Edwards, A. C. Brown, J. Y. Huang and M. A. Kainer, 2018. Vital signs: containment of novel multidrug-resistant organisms and resistance mechanisms-United States, 2006-2017. Morbidity and Mortality Weekly Report, 67(13), 396.

37. Sader, H. S., P. R. Rhomberg, R. K. Flamm, R. N. Jones and M. Castanheira, 2017. WCK 5222 (cefepime/zidebactam) antimicrobial activity tested against Gram-negative organisms producing clinically relevant $\beta$-lactamases. Journal of Antimicrobial Chemotherapy, 72(6), 1696-1703.

38. Srinivas, P and K. Rivard, (2017). Polymyxin resistance in Gram-negative pathogens. Current Infectious Disease Reports, 19(11), 38.

39. Chew, K. L., M. V. La, R. T. Lin and J. W. Teo, 2017. Colistin and polymyxin B susceptibility testing for carbapenemresistant and mcr-positive Enterobacteriaceae: comparison of Sensititre, MicroScan, Vitek 2, and Etest with broth microdilution. Journal of clinical microbiology, 55(9), 2609-2616.

40. Roberts, M. C and S. Schwarz, 2017. Tetracycline and chloramphenicol resistance mechanisms. In Antimicrobial Drug Resistance Springer, Cham, pp. 231-243. 